\title{
Identifying Key Factors towards Highly Reflective Silver Coatings
}

\author{
Bo Zheng, ${ }^{1,2}$ Lai Peng Wong, ${ }^{1}$ Linda Y. L. Wu, ${ }^{3}$ and Zhong Chen ${ }^{2}$ \\ ${ }^{1}$ MacDermid Enthone, MacDermid Performance Solutions, 26 Tuas West Road, Singapore 638382 \\ ${ }^{2}$ School of Materials Science and Engineering, Nanyang Technological University, 50 Nanyang Avenue, Singapore 639798 \\ ${ }^{3}$ Singapore Institute of Manufacturing Technology, 2 Fusionopolis Way, No. 08-04, Innovis, Singapore 138634
}

Correspondence should be addressed to Bo Zheng; bzheng002@ntu.edu.sg and Zhong Chen; aszchen@ntu.edu.sg

Received 31 May 2017; Accepted 5 July 2017; Published 18 September 2017

Academic Editor: Francesco Ruffino

Copyright (C) 2017 Bo Zheng et al. This is an open access article distributed under the Creative Commons Attribution License, which permits unrestricted use, distribution, and reproduction in any medium, provided the original work is properly cited.

\begin{abstract}
This paper attempts to identify key factor(s) for highly reflective silver (Ag) coatings. Investigation was made over the crystal orientation and surface roughness, using several types of surfaces, including electroplated Ag polycrystal films, physical vapour deposited polycrystal Ag films, and single crystal Ag foils with different crystal orientations. In each type of the surfaces, surface roughness was varied so that, for different combinations of crystal orientation, roughness would elucidate the key factors towards highly reflective Ag coatings. It is found that surface roughness plays a critical role in determining the reflectance, while the crystal orientation has negligible effect. The mean reflectance and one-way ANOVA analysis indicate that the single crystal Ag foils with three orientations performed statistically the same in the same roughness group at significance level $\alpha=0.05$. Moreover, correlation between the surface reflectance and surface roughness has been proposed for the benefit of coating design. Refection data obtained from the polycrystalline silver samples are used to verify the accuracy of the proposed correlations. It was observed that the development surface area ratio, $S_{d r}$, is a better roughness indicator in predicting the reflectance of polycrystalline silver films than the arithmetic average roughness, $R_{a}$.
\end{abstract}

\section{Introduction}

In recent years, high brightness light emitting diodes (HB LEDs) which emit white light have been expanding their markets to replace incandescent and halogen bulbs for general illuminations applications because of their higher efficiencies and are more pleasing to the eyes [1]. An LED consists of lead frame, in which a light emitting semiconductor chip is positioned, and epoxy encapsulation. Since the light emitting chip is placed on the lead frame, the lead frame must have excellent electrical, thermal, and reflective properties [2]. High light extraction efficiency is one of the critical performance indicators for HB LEDs. Due to the large contrast in the refractive indices among the different materials used, certain amount of the emitted photons within the LED chip is trapped by its internal reflection. As a result, the amount of light output is reduced. Improving the light extraction efficiency is vital for the development of HB LEDs. One of the methods is to reduce the light scattering by depositing a highly reflective silver $(\mathrm{Ag})$ thin film on the lead frame surface [3-8]. The Ag layer also serves the purpose of enhancing the solderability and heat dissipation of the lead frame.

On the other hand, plasmon, a quantum of plasma oscillation, has also played more and more important role in studying the properties of metals and semiconductors. Surface plasmon resonance technology has been widely used in high resolution lithography, sensing, and microscopy [911]. Recently, this technology has also been used to improve the emission efficiency of organic LED for developing high brightness LEDs [12]. However, as surface plasmon resonance technology is still not widely accepted in the lead frame industries, this technology is under consideration of the current work.

Many metals have good reflection of light. The reason that $\mathrm{Ag}$ is selected among different metallic materials is due to its high theoretical reflectance of up to $95 \%$ in the visible light 
wavelength region and its ability to form a smooth coating. The excellent reflective characteristics of Ag can help improve the LED luminous efficiency $[13,14]$.

In lead frame industries, the lead frame substrates will be pretreated chemically to obtain a smoother surface. After that, highly reflective Ag coating will be electrodeposited on the substrate with the aid of suitable brighteners, levellers, and wetting agents. These additives are proprietary information by the suppliers. Besides the plating chemistry, the operating conditions such as $\mathrm{pH}$, temperature, current density, and agitation will also greatly affect the quality of the Ag coating [15].

$\mathrm{Ag}$ is chosen because it has the highest theoretical reflectivity of visible light among all metals. However since the cost of $\mathrm{Ag}$ is high too, ways to save the cost of raw material or the production cost have been explored by the industry. For example, spot plating can selectively electrodeposit silver on specific functional areas instead of the entire lead frame surfaces. In this way, the amount of Ag deposited on the nonfunctional areas of the lead frame can be significantly reduced, resulting in lower production cost. In addition, high speed silver plating, which can help to improve the productivity, is preferred in order to reduce the mass production cost.

In general, the reflectance of a metal is governed by the amount of light reflected off the metal specularly [17]. The relationship between the microstructure and brightness of electroplated nickel has been reported few decades ago [18]. This study has shown the effect of grain size, crystal texture, and surface morphology of nickel surface on its light reflecting capability. The study has also confirmed that not all fine-grained deposits are bright.

On the other hand, the structural criteria for a metal surface to show mirror brightness were previously characterized by Nikolić et al. via their scanning tunneling microscopy (STM) as well as atomic force microscopy (AFM) studies $[17,19,20]$. First, mirror brightness is governed by flat and mutually parallel parts of the metal surface which exhibit smoothness at the atomic level; second, there are distances of about several atomic diameters between the adjacent flat parts of the surface [19]. However, the correlation between the crystal growth and crystal orientation of silver coating and its reflection was not examined in that study. Besides, polycrystalline films are normally used in the previous research.

The aim of the current study is to identify key factor(s) behind Ag reflection of visible light. Potential factors include crystal orientation, crystal size, and surface roughness. The correlation between crystal orientation and reflectance of silver film needs to be confirmed by separating the influence of surface roughness. This can be best achieved using single crystal Ag with different crystal orientation but with controllable surface roughness.

In this study, high purity single crystal Ag foils with specific orientations of the (100), (110), and (111) crystal planes will be used to study the relationship between the crystal orientation and the light reflectance. Attention will be paid to the individual effect of the crystal orientation and surface topological factor. The comprehensive studies of surface topography and surface texture on the optical properties of single crystal Ag surfaces can provide more affirmative guidance to the practical manufacturing of polycrystalline Ag films. In addition, polycrystalline Ag films were produced by physical vapour deposition and electroplating. Reflectance data from these polycrystalline Ag surfaces are used to verify the findings and correlation models derived from the single crystal study.

\section{Experimental}

2.1. Materials. High purity (99.999\%) silver single crystals with specific orientations of the (100), (110), and (111) were purchased from Goodfellow Cambridge, Ltd., UK. These onesided polished single crystals have diameter of $10 \mathrm{~mm}$ and thicknesses of $2 \mathrm{~mm}$ for the (100) and (111) samples and $1 \mathrm{~mm}$ for the (110) sample. The orientation tolerance of these single crystals was $\pm 3^{\circ}$.

The relationship between the surface structural characteristics of single crystals and their optical properties was studied by carefully varying the surface roughness of single crystals. This was carried out by grinding/polishing machine (TegraPol-21, Struers) at room temperature.

Brass panels (Kocour) were used as substrates for preparing electroplated and physical vapour deposited Ag films. Before the film deposition, the brass panels were soak cleaned, electrolytic cleaned, and etched in Enprep 110 EC, Enprep 220 EC (MacDermid Enthone), and $10 \% \mathrm{H}_{2} \mathrm{SO}_{4}$ in sequence prior to use. After the cleaning and etching step, a thin layer of $\mathrm{Ni}$ was electrodeposited on the cleaned brass panels using Lectro-Nic 10-03 (MacDermid Enthone) at $55^{\circ} \mathrm{C}$, with a current density at $0.12 \mathrm{~A} / \mathrm{cm}^{2}$. The nickel thickness was measured by fluorescent X-ray coating thickness measurement gauge (Seiko SFT 9300) and was controlled in the range of $0.55-0.75 \mu \mathrm{m}$. The electrodeposited silver was prepared by a plating facility (XRD Ag-7000, MacDermid Enthone) at $57^{\circ} \mathrm{C}$, under $0.3 \mathrm{~A} / \mathrm{cm}^{2}$ current density. The thickness of the $\mathrm{Ag}$ films was controlled within $2-2.5 \mu \mathrm{m}$ while the different roughness of Ag films was obtained by controlling the brightener levels in the Ag electrolyte and current densities.

Physical vapour deposited (PVD) Ag films were prepared using UDP 550 - 4, TCL. Similar to the electrodeposition, a layer of $\mathrm{Ni}(0.55-0.75 \mu \mathrm{m})$ was electrodeposited on the brass panels following the same procedures. Before the deposition, middle frequency hydrogen plasma etching was used to remove native oxides so as to leave a clean and chemically balanced $\mathrm{Ni}$ surface. The etching time was $30 \mathrm{~min}$ at $8.0 \times$ $10^{-4}$ torr. After that, sputtering was carried out using alternate current (AC) at $50 \mathrm{~Hz}$. The chamber pressure was kept at 1.7 $\times 10^{-3}$ torr during sputtering, and the applied voltage and current were $60 \mathrm{~V}$ and $0.2 \mathrm{~A}$, respectively. The thickness of each Ag film was controlled around $2.0-2.5 \mu \mathrm{m}$. As the PVD deposition follows the Ni surface morphology underneath the Ag film, the different roughness of Ag films was obtained by controlling the roughness of deposited Ni layer.

2.2. Optical Reflectivity. The specular reflectance (SR) was measured by spectroscopic reflectometer (Raditech, Taiwan) at a light incidence angle of $0^{\circ}$. A crystalline silicon wafer 
was used as a standard reference. Intensity change of the light reflected from the surface was measured as a function of wavelength $(\lambda=300 \mathrm{~nm}-1000 \mathrm{~nm})$ at normal incidence. The specular reflectance of silver could be readily calculated based on the optical constant of silicon. Reflectance readings were taken at $\lambda=450 \mathrm{~nm}$ and $550 \mathrm{~nm}$ because these two wavelengths are critical in the LED application, accounting for the centre emission wavelength of, respectively, the blue and green light of a white light LED. The average reflectance of five locations on each Ag surface was reported.

2.3. Materials Characterization. X-ray diffraction was conducted for the crystal structure and orientation of the samples. LabX XRD (XRD-6000, Shimadzu) with $\mathrm{Cu} \mathrm{K}_{\alpha}$ radiation $(40 \mathrm{kV}, 30 \mathrm{~mA})$ was used. The samples were scanned using the $\theta-2 \theta$ method at a scan rate of $2^{\circ} \mathrm{min}^{-1}$.

The surface morphology was observed under scanning electron microscope (SEM, JSM - 6360A, JEOL). Elemental analysis was done using the energy-dispersive X-ray spectroscopy (EDX) attached to the SEM.

2.4. Surface Topology. The surface roughness was measured using AFM (DI-3100, Digital Instruments). The average of five surface roughness measurements was taken for each sample.

The quantitative surface roughness analysis was done reporting the arithmetic average roughness $\left(R_{a}\right)$. In addition, $S_{d r}$, the developed surface area ratio, was also reported in this work with its correlation with the light reflection studied. $S_{d r}$ is defined as the ratio of developed $3 \mathrm{D}$ surface area to the planar area $[21,22]$ and could potentially represent the surface feature better than $R_{a}$.

\section{Results and Discussions}

3.1. Microstructure and Surface Texture Analysis. The crystal structure of the three commercially available single crystals $\mathrm{Ag}$, electrodeposited $\mathrm{Ag}$, and physical vapour deposited Ag samples was examined using X-ray diffraction (XRD). Figure 1 shows that the three Ag crystal samples display only (200), (220), and (111) diffraction peaks, respectively, which indicates that each sample indeed exhibits single crystal orientation. On the other hand, the XRD patterns of an electrodeposited and the PVD Ag films show four diffraction peaks, namely, the (111), (200), (220), and (311) peaks. This indicates that the electrodeposited and PVD Ag films are polycrystalline. It was noted that the XRD peaks of the electroplated Ag film are broader than the ones of the PVD counterpart, indicating slightly poor crystallinity of the former.

In order to correlate the crystal orientation and reflectance of $\mathrm{Ag}$ crystals, the influence of their surface morphology (or roughness) on the reflectance must be eliminated. Hence, Ag crystals with three specific single crystal orientations but with controllable surface roughness parameter were utilized.

The three Ag (100), Ag (110), and Ag (111) crystals were either polished or roughened to different roughness, which could be quantitatively categorized into five groups, that is,

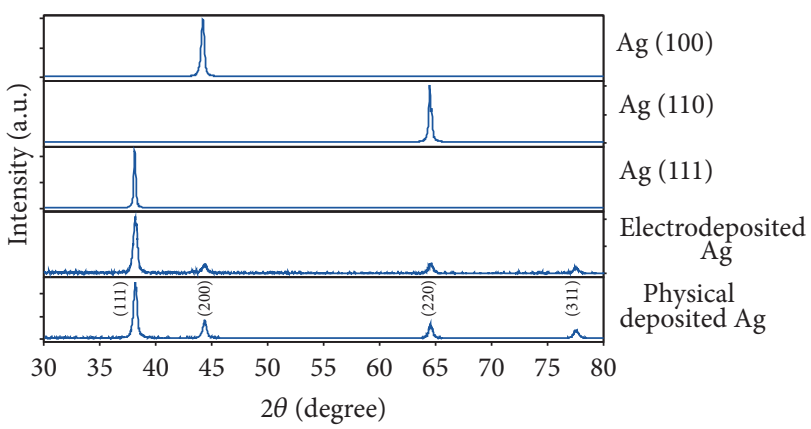

FIGURE 1: XRD patterns of Ag (100), Ag (110), and Ag (111) crystals as well as the electrodeposited and PVD polycrystalline silver films.

(A1) $R_{a}=0.00-5.00 \mathrm{~nm}$; (B1) $R_{a}=5.01-10.00 \mathrm{~nm}$; (C1) $R_{a}$ $=10.01-20.00 \mathrm{~nm}$; (D1) $R_{a}=20.01-30.00 \mathrm{~nm}$; and (E1) $R_{a}$ $=30.01-45.00 \mathrm{~nm}$, as summarized in Table 1 . The average $R_{a}$ of the crystals were obtained by AFM analysis and they represent the arithmetic average of the variations in the height of the surface relative to a reference plane [23]. The average $R_{a}$ for $\mathrm{A} 1, \mathrm{~B} 1, \mathrm{C} 1, \mathrm{D} 1$, and $\mathrm{E} 1$ groups were determined to be $3.2 \pm 1 \mathrm{~nm}, 6.6 \pm 2 \mathrm{~nm}, 12.8 \pm 2 \mathrm{~nm}, 26.5 \pm 3 \mathrm{~nm}$, and $36.2 \pm$ $5 \mathrm{~nm}$. The 3D AFM images in Table 1 also portray the surface topographies of the Ag crystals with different $R_{a}$ roughness.

3.2. Reflection Characteristics. Specular reflectance is a numerical value of the visual brightness or mirror quality of a surface [24]. The reflectance of a sample can be determined by the ratio of reflected light intensity over incident light intensity. However, in practice, it is difficult to determine the incident light intensity before it strikes onto the sample surface. Hence, a relative intensity is first calculated whereby the reflected light intensity from the sample is divided by the incident light intensity from a standard. For the specular reflectance measurement, the change in reflected light intensity is detected while the incidence angle is $0^{\circ}$. Since the optical constants of silicon are well understood, the specular reflectance of the sample can be readily calculated from these known values [25].

From Figure 2, the $\mathrm{Ag}(100), \mathrm{Ag}(110)$, and $\mathrm{Ag}$ (111) crystals with $R_{a}=0.00-5.00 \mathrm{~nm}$ show very high specular reflectance $\sim$ $90 \%$ over $\lambda=400-800 \mathrm{~nm}$. This result is quite consistent with the reflectance of silver metal obtained from the literature [16]. Depending on the radiation wavelength, metals respond differently; that is, their reflectivity varies with the wavelength of incident light. Even though silver has very high reflectivity over the visible light region, its reflectivity decreases significantly under the exposure of short optical wavelength radiation, particularly those below $500 \mathrm{~nm}$. This is because, in this blue light region, the refractive index of silver is increased slightly which in turn affects the silver reflectivity $[26,27]$.

Previous studies $[28,29]$ have confirmed that perfectly smooth surfaces allow specular (mirror-like) reflection which obeys law of reflection; that is, the angle of incident beam is equal to the angle of reflected beam, whereas rough surfaces cause diffuse reflection as the incident beams are reflected 
TABLE 1: The surface roughness of $\mathrm{Ag}(100), \mathrm{Ag}(110)$, and $\mathrm{Ag}(111)$ crystals was quantitatively categorized into five different groups, that is, (A1) $R_{a}=0.00-5.00 \mathrm{~nm}$; (B1) $R_{a}=5.01-10.00 \mathrm{~nm} ;(\mathrm{Cl}) R_{a}=10.01-20.00 \mathrm{~nm}$; (D1) $R_{a}=20.01-30.00 \mathrm{~nm}$; and (E1) $R_{a}=30.01-45.00 \mathrm{~nm}$. Their average $R_{a}$ were determined from the AFM analysis.

Group Measured average

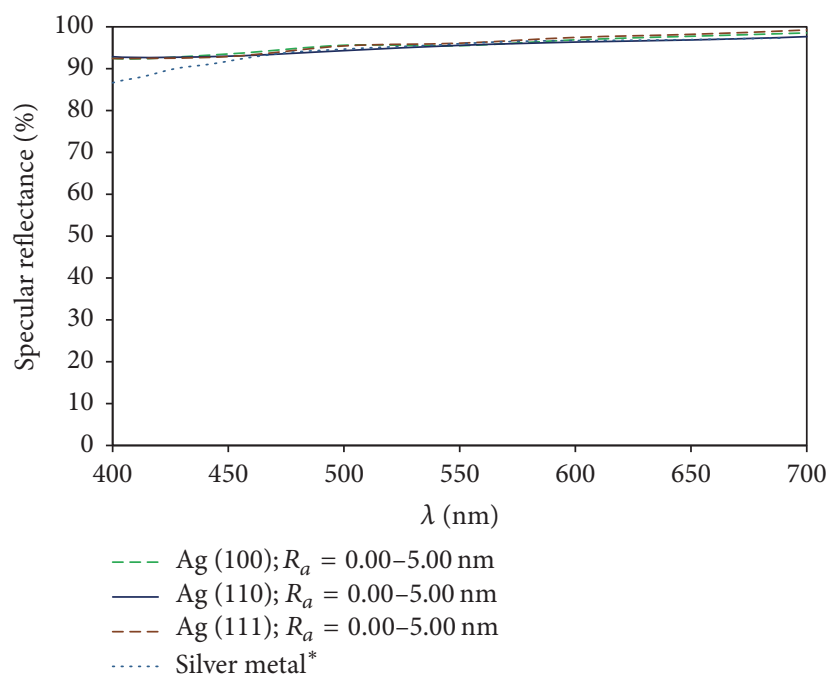

Figure 2: Specular reflectance (SR) versus wavelength spectrum of Ag (100), (110), (111) crystals with $R_{a}=0.00-5.00 \mathrm{~nm}$ and silver metal. *The reflectance of silver metal was obtained from the literature values of silver optical constants published by Palik [16]. 


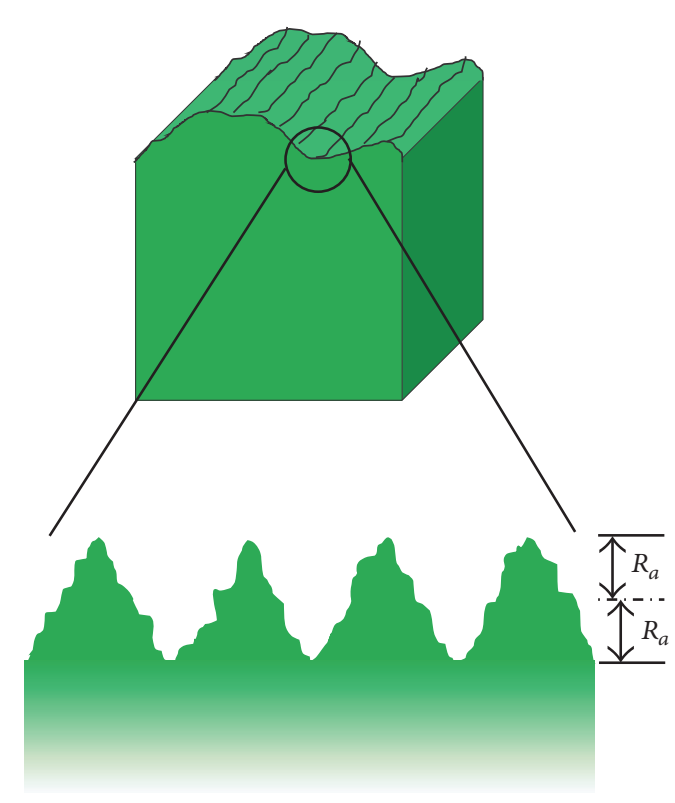

(a)

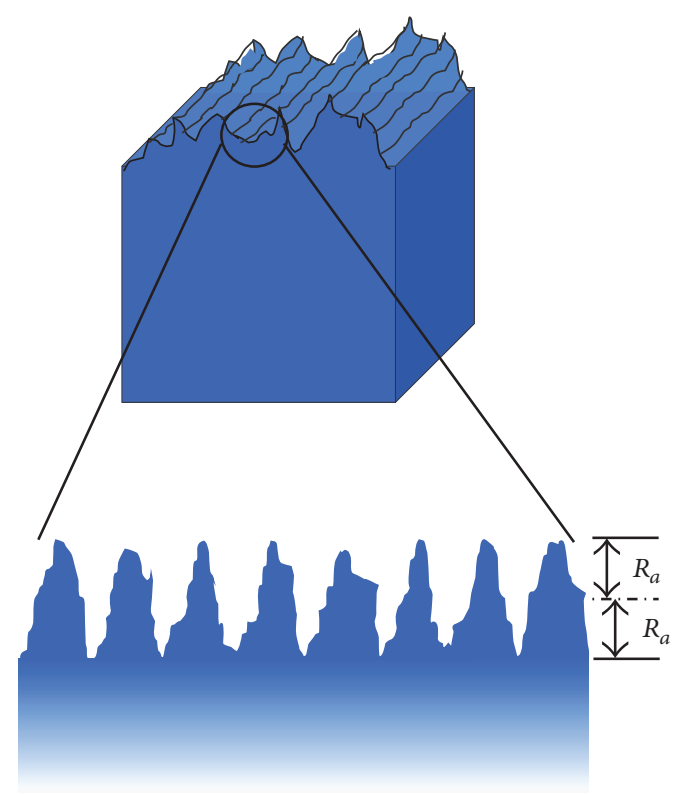

(b)

SCHEME 1: Schematic illustration of different surface profiles having the same $R_{a}$ value.

in various directions. When the surface roughness increases, reflected light becomes more diffusive so the surface looks matt or dull. As a consequence, the surface roughness of the Ag sample could significantly affect its reflective characteristics.

3.3. Surface Topography Measurement and Reflectance. In most cases, surface roughness is often denoted by average $R_{a}$, which is the most commonly used roughness parameter in specifying the quality of a material surface. In addition to $R_{a}$, other roughness parameters, such as $R_{q}$ (root-mean-square), $R_{\max }$ (difference in height between the highest and lowest points on the surface relative to the reference plane), and $R_{z}$ (the average absolute value of the five highest and five lowest points), are also widely used to describe the vertical characteristics of a material surface.

Although $R_{a}$ has been employed as a general guideline in characterizing surface texture in most industries for decades, $R_{a}$ alone is not sufficient to provide a comprehensive surface profile of a material. This is because $R_{a}$ result does not provide lateral information and $R_{a}$ values cannot differentiate surfaces with different features between peaks and valleys, which are critical in determining the surface reflection of light. Surfaces with protruding peaks, cavity, and other irregularities may give the same average $R_{a}$ value. For example, Schemes 1 (a) and 1(b) depict different surface profiles having the same $R_{a}$ value but the reflectance may be different from the two surfaces.

Hence, developed interfacial area ratio $\left(S_{d r}\right)$, or more appropriately for the current context, the developed surface area ratio, is considered in this study. $S_{d r}$ describes the change in $3 \mathrm{D}$ surface area relative to the $2 \mathrm{D}$ planar surface area. In contrast to $R_{a}$ which does not provide detailed information on the $3 \mathrm{D}$ surfaces, $S_{d r}$ is able to characterize the $3 \mathrm{D}$ surface topography of materials. The surface area includes the influence of variation in the height and number of peaks. $S_{d r}$ is defined as follows:

$$
S_{d r}=\frac{(\text { Texture surface area }- \text { Planar area }) * 100 \%}{\text { Planar area }} .
$$

Similar to $R_{a}$, the effect of $S_{d r}$ on the reflectance is studied by categorizing the $S_{d r}$ values obtained from the AFM measurement into 6 different groups, that is, (A2) $S_{d r}$ $=0.00-0.50 \%$; (B2) $S_{d r}=0.51-1.00 \%$; (C2) $S_{d r}=1.01-2.00 \%$; (D2) $S_{d r}=2.01-3.00 \%$ and (E2) $S_{d r}=3.01-4.00 \%$; (F2) $S_{d r}$ $=4.01-5.00 \%$. The average $S_{d r}$ for groups A2, B2, C2, D2, $\mathrm{E} 2$, and F2 were determined to be $0.3 \pm 0.04 \%, 0.7 \pm 0.05 \%$, $1.5 \pm 0.27 \%, 2.18 \pm 0.07 \%, 3.18 \pm 0.1 \%$, and $4.48 \pm 0.09 \%$, respectively.

The reflectance at $\lambda=450$ and $550 \mathrm{~nm}$ is used for comparison. A decrease in specular reflectance was observed and this is associated with an increase in surface roughness, regardless of the fact that it is expressed either in $R_{a}$ (Figures 3(a) and 3(b)) or in $S_{d r}$ (Figures 3(c) and 3(d)). The high $R^{2}$ of the regression equations in Figure 3 have indicated that the relationship between the surface roughness and reflectance can be well described as a linear relationship.

Although the roughness affects both the specular reflectance at $450 \mathrm{~nm}$ and at $550 \mathrm{~nm}, R_{550 \mathrm{~nm}} \%$ is always higher than $R_{450 \mathrm{~nm}} \%$ because of the blue light effect explained above.

The SEM images of Ag (100), Ag (110), and Ag (111) crystals have also confirmed that the decrease in specular 


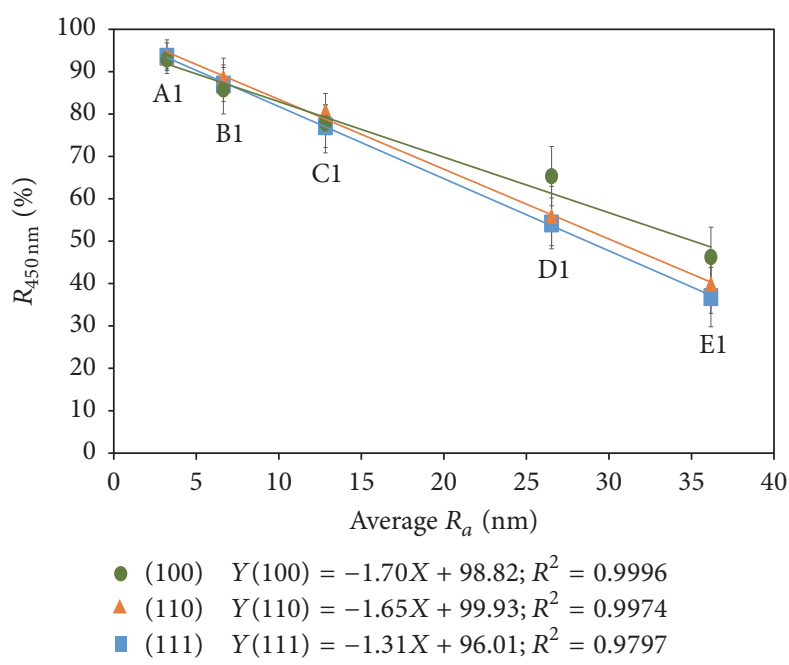

(a)

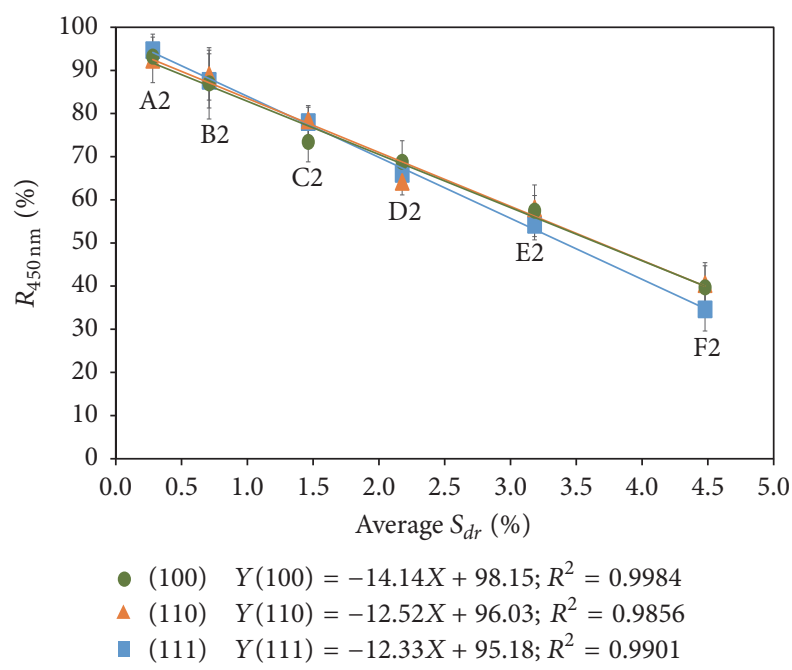

(c)

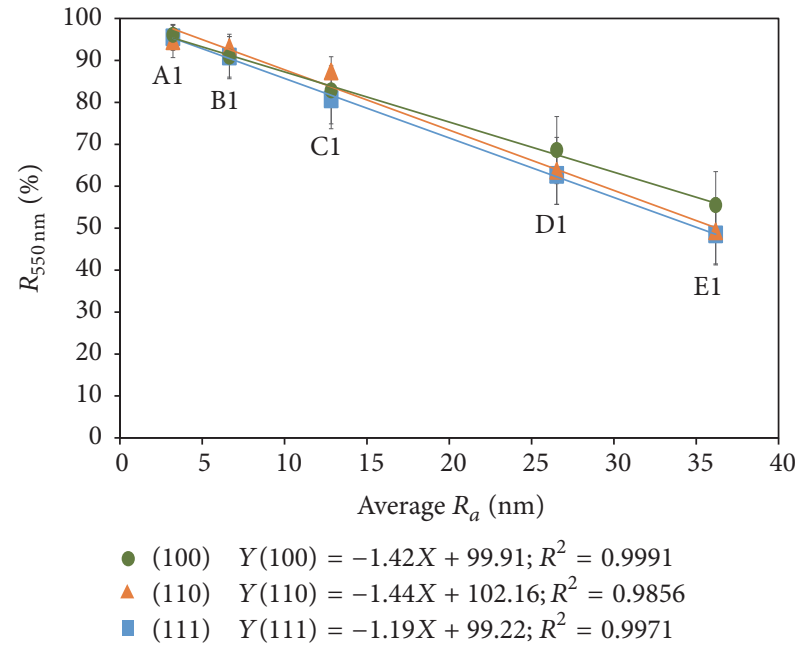

(b)

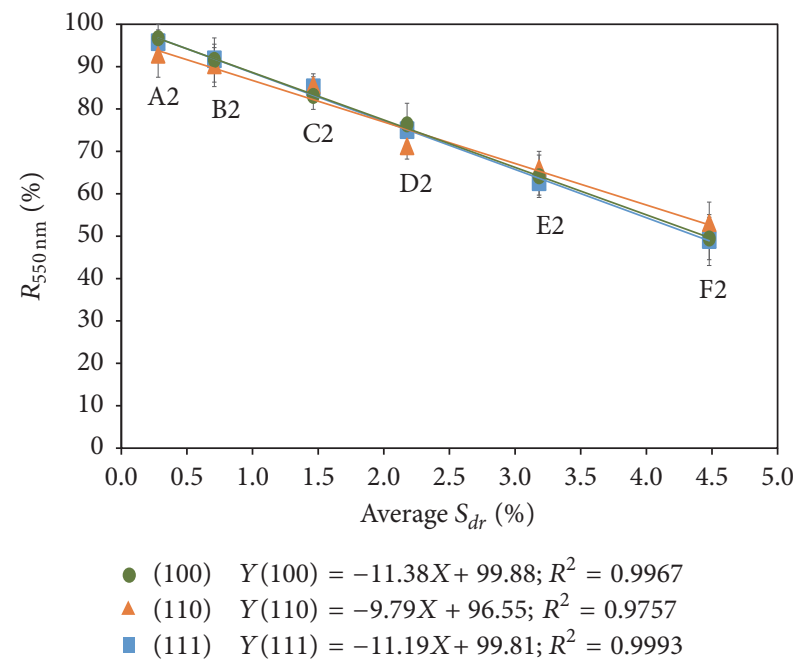

(d)

FIGURE 3: The dependence of specular reflectance on (a-b) the average $R_{a}$ for Groups A1-E1; (c-d) the average developed interfacial area ratio $\left(S_{d r}\right)$ values for Groups A2-F2 of $\mathrm{Ag}(100), \mathrm{Ag}(110)$, and $\mathrm{Ag}(111)$ crystals at $\lambda=450 \mathrm{~nm}$ and $550 \mathrm{~nm}$, respectively.

reflectance is greatly associated with an increase in irregularities in the surface morphologies of the single crystals as shown in Figure 4.

\subsection{Correlation between Crystal Orientations and Their Reflec-} tion. Figure 3 has confirmed that both $R_{a}$ and $S_{d r}$ could be used as roughness indicators to represent the surface topology of single crystals. Hence, the effects of crystal orientations on the reflectance are also investigated based on these two indicators. From Figures 5(a) and 5(b), it seems that there is no significant difference in reflectance among the three single crystals at both $450 \mathrm{~nm}$ and $550 \mathrm{~nm}$ wavelengths for Groups A1-C1, while Ag (111) may exhibit slightly higher reflectance when compared to $\mathrm{Ag}$ (100) and $\mathrm{Ag}$ (110) in Groups D1-E1. Hence, the mean and one-way ANOVA of $R_{450 \mathrm{~nm}} \%$ and $R_{550 \mathrm{~nm}} \%$ among Groups A1-E1 are evaluated and their results are shown in Table 2. The one-way ANOVA has indicated that it is likely that there is no statistically significant difference in the means $R_{450 \mathrm{~nm}} \%$ and $R_{550 \mathrm{~nm}} \%$ as their $P$ values $>0.05$ (significance level set for one-way ANOVA) among Ag (100), Ag (110), and Ag (111) for all Groups A1-E1.

On the other hand, when $S_{d r}$ is used as a roughness indicator to represent the surface topology of these $\mathrm{Ag}$ crystals, Figures 5(c) and 5(d) have also shown that there is not much difference in reflectance among Ag (100), Ag (110), and $\mathrm{Ag}$ (111) for similar $S_{d r}$. Table 3 shows the mean and one-way ANOVA of $R_{450 \mathrm{~nm}} \%$ and $R_{550 \mathrm{~nm}} \%$ among Groups A2-F2. The one-way ANOVA has also indicated that the means $R_{450 \mathrm{~nm}} \%$ and $R_{550 \mathrm{~nm}} \%$ of $\mathrm{Ag}(100), \mathrm{Ag}$ (110), and $\mathrm{Ag}$ (111) are statistically the same $(P>0.05)$. Both $R_{a}$ and $S_{d r}$ indicators are independent of the wavelengths.

Tables 2 and 3 have clearly shown that there is no strong correlation between crystal orientation and reflectance. This 


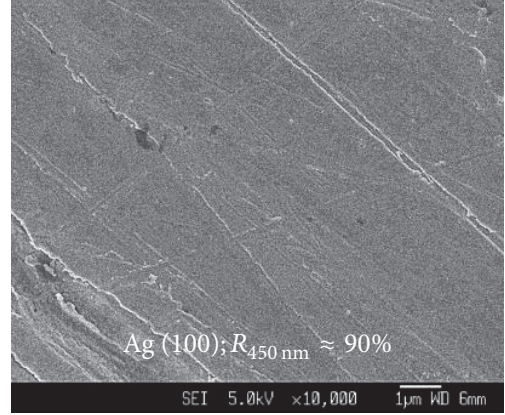

(a)

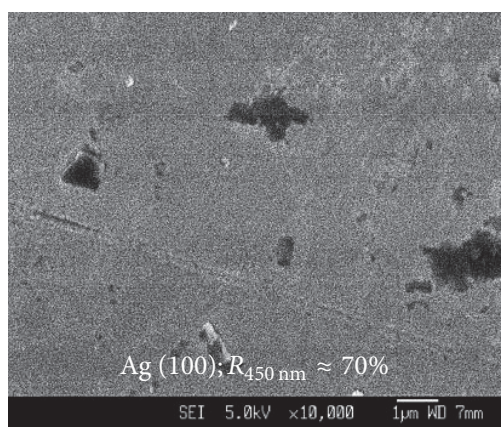

(d)

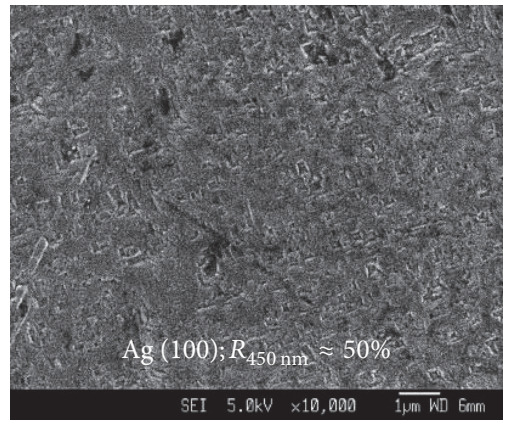

(g)

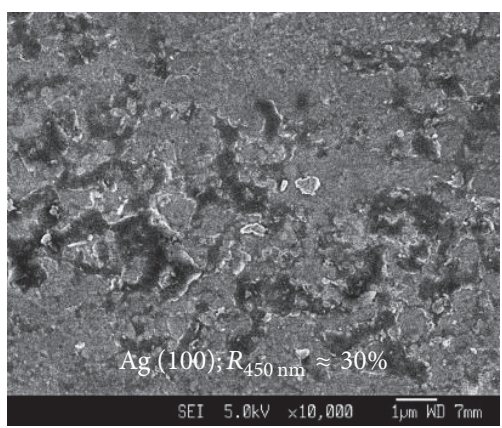

(j)

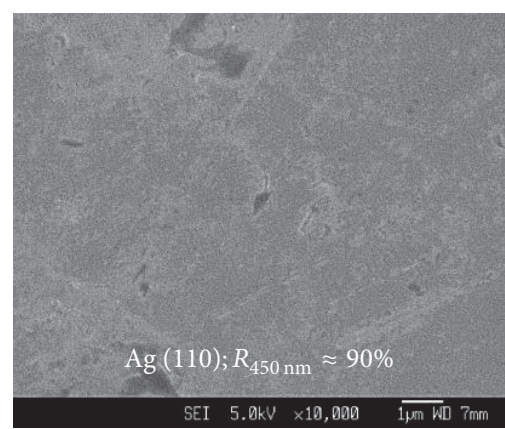

(b)

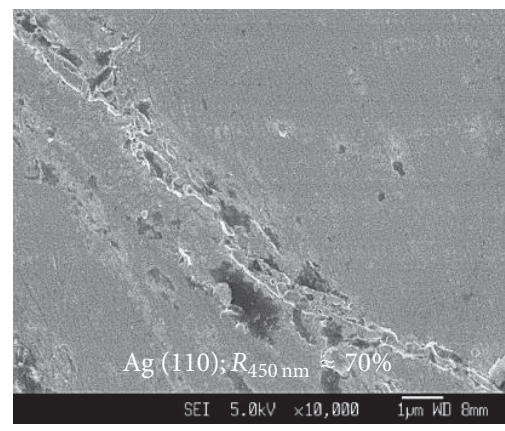

(e)

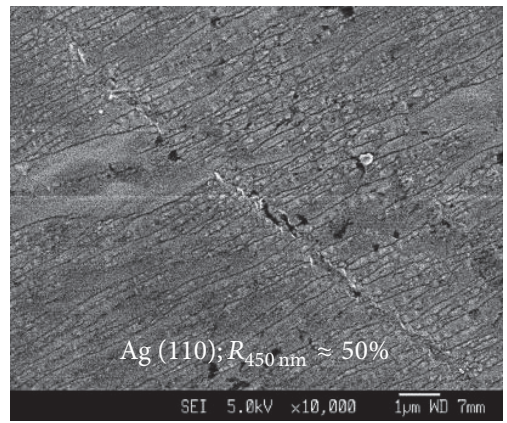

(h)

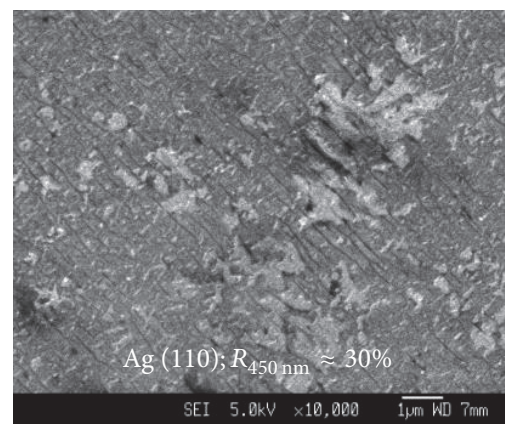

(k)

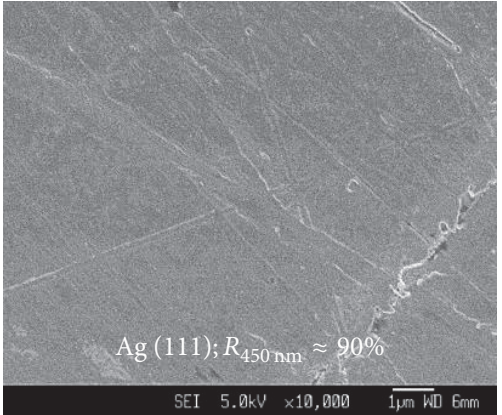

(c)

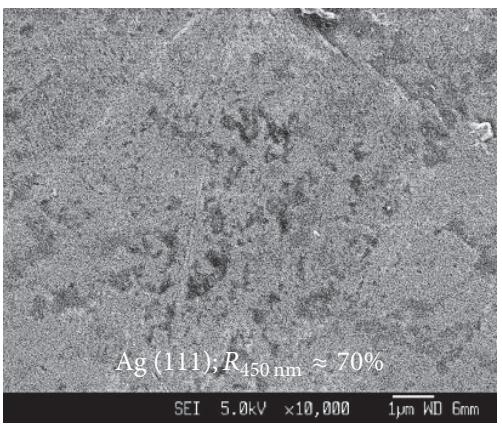

(f)

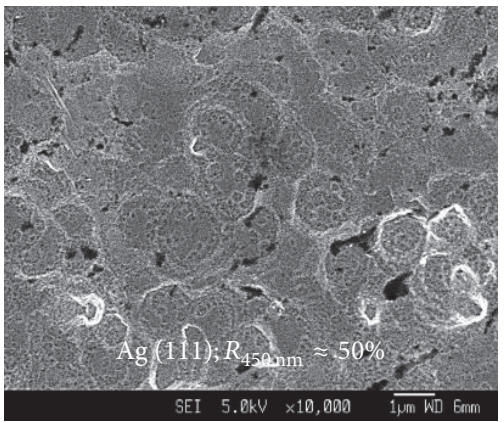

(i)

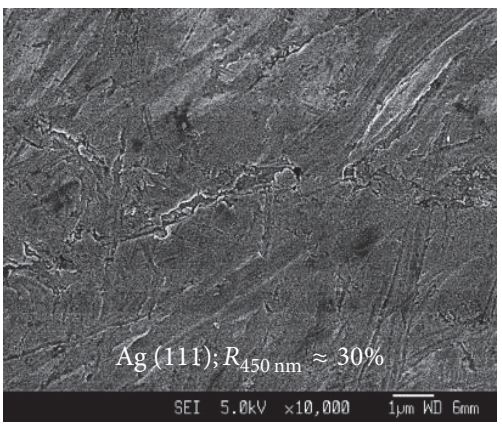

(l)

Figure 4: Surface morphologies of single crystal Ag (100), Ag (110), and Ag (111) with different specular reflectance (a)-(c) $R_{450 \mathrm{~nm}} \approx 90 \%$; (d)-(f) $R_{450 \mathrm{~nm}} \approx 70 \%$; (g)-(i) $R_{450 \mathrm{~nm}} \approx 50 \%$; (j)-(l) $R_{450 \mathrm{~nm}} \approx 30 \%$.

suggests that it is the surface roughness that has the main effect in controlling the reflectance of Ag rather than the way crystallites orient themselves at microscale. Assuming that the reflectance measurement of the (100), (110), and (111) surfaces at normal incidence is optically isotropic, the factor that influences the differences in reflectance should be from the irregularities of material surface. Moreover, although a single crystal with (100), (110), or (111) orientations exhibits 


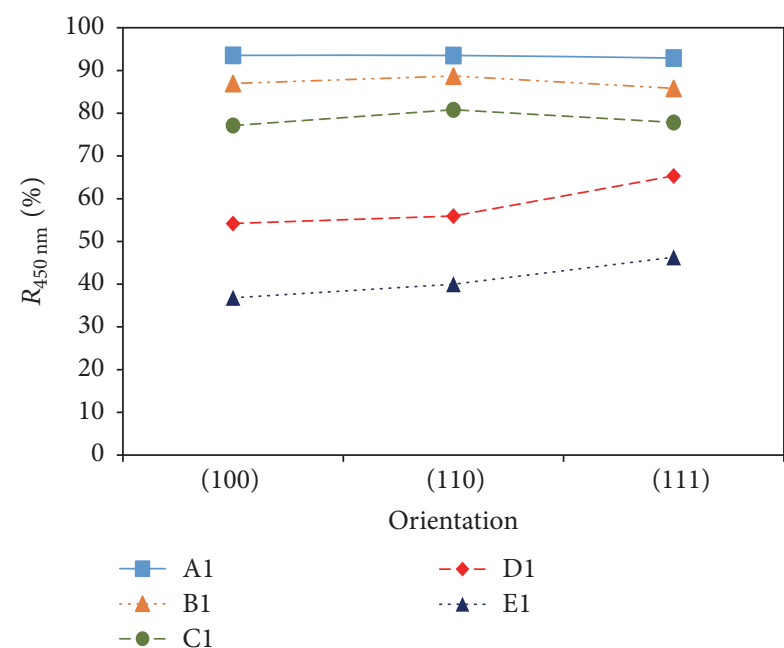

(a)

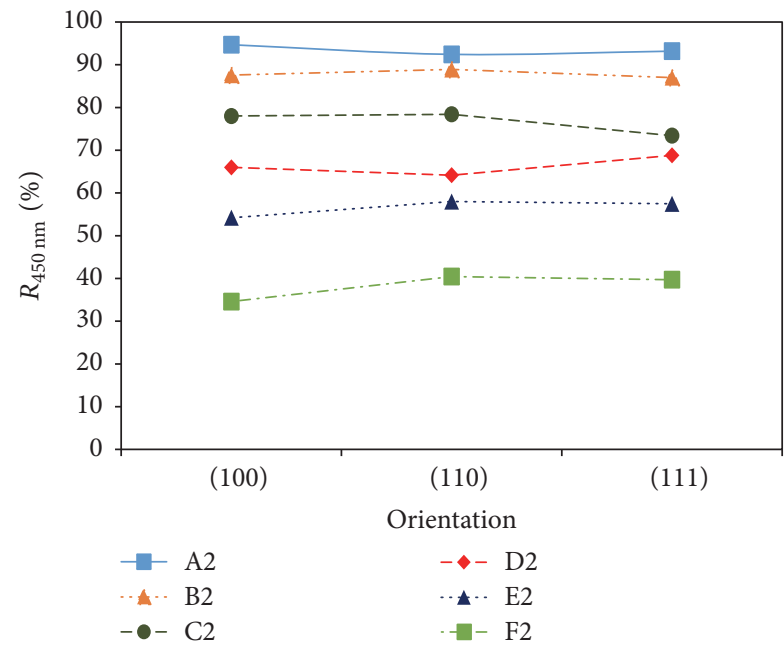

(c)

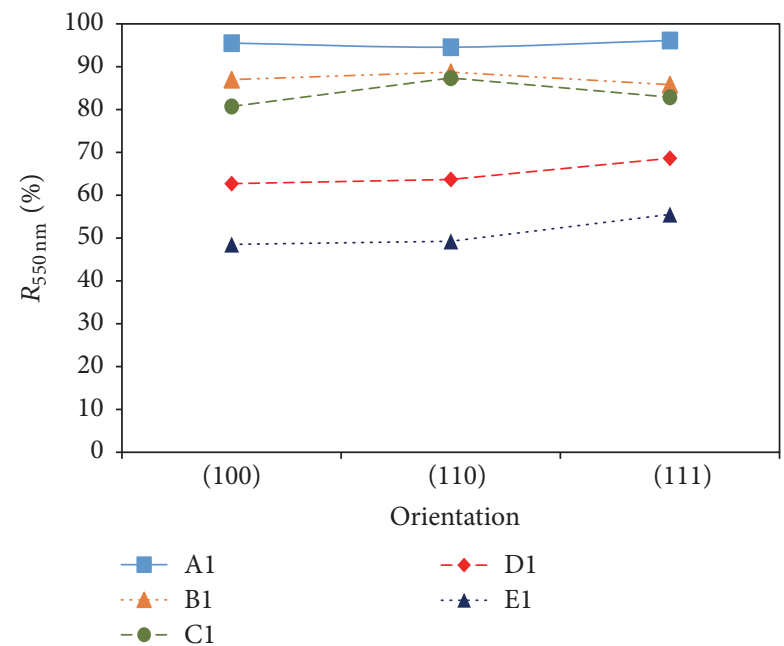

(b)

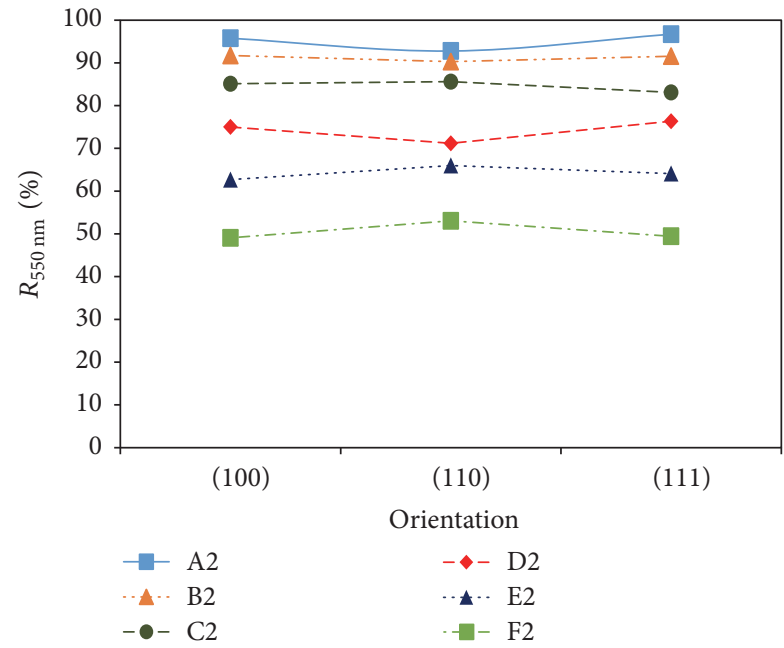

(d)

Figure 5: The effects of the Ag crystal orientations (100), (110), and (111) on the specular reflectance for different (a-b) $R_{a}$ and (c-d) $S_{d r}$ groups at $\lambda=450 \mathrm{~nm}$ and $550 \mathrm{~nm}$, respectively.

TABLE 2: Mean and one-way ANOVA of $R_{450 \mathrm{~nm}} \%$ and $R_{550 \mathrm{~nm}} \%$ among Groups A1-E1. Significance level $\alpha=0.05$.

\begin{tabular}{lcccccccc}
\hline Group & \multicolumn{3}{c}{ Mean $R_{450 \mathrm{~nm}} \% \pm \mathrm{SD}$} & ANOVA $\left(R_{450 \mathrm{~nm}} \%\right)$ & \multicolumn{3}{c}{ Mean $R_{550 \mathrm{~nm}} \% \pm \mathrm{SD}$} & \multicolumn{2}{c}{ ANOVA $\left(R_{550 \mathrm{~nm}} \%\right)$} \\
& $(100)$ & $(110)$ & $(111)$ & $P$ & $(100)$ & $(110)$ & $(111)$ & $P$ \\
\hline A1 & $93.5 \pm 3$ & $93.5 \pm 3$ & $92.9 \pm 2$ & 0.745 & $94.5 \pm 4$ & $94.5 \pm 4$ & $96.1 \pm 2$ & 0.261 \\
B1 & $86.9 \pm 5$ & $88.7 \pm 4$ & $85.8 \pm 6$ & 0.571 & $90.9 \pm 4$ & $93.2 \pm 2$ & $90.9 \pm 5$ & 0.463 \\
C1 & $76.6 \pm 3$ & $79.7 \pm 3$ & $76.1 \pm 4$ & 0.332 & $81.0 \pm 5$ & $86.1 \pm 2$ & $84.2 \pm 3$ & 0.113 \\
D1 & $54.8 \pm 7$ & $56.9 \pm 8$ & $63.3 \pm 7$ & 0.176 & $63.1 \pm 6$ & $64.5 \pm 8$ & $69.7 \pm 8$ & 0.179 \\
E1 & $37.8 \pm 5$ & $39.4 \pm 3$ & $47.6 \pm 7$ & 0.251 & $47.3 \pm 4$ & $48.0 \pm 7$ & $53.6 \pm 8$ & 0.627 \\
\hline
\end{tabular}

different surface symmetry and atoms arrangement if viewed from normal incidence, it is the microscopic roughness of the Ag surface that has caused the light scattering. When the microscopic roughness is much smaller than the wavelength, the light is reflected specularly from the surface.

3.5. Correlation Models. The individual effect of the three crystal orientations and their surface topological factors have been discussed above. Figure 5 shows that there is no significant and direct correlation between crystal orientation and reflectance; the orientation contribution towards the reflectance is neglected in developing the statistical model.

The statistical model is built based on the linear regression analysis of the surface roughness. Since $R_{a}$ and $S_{d r}$ are the results of $2 \mathrm{D}$ and $3 \mathrm{D}$ roughness measurements of the surface texture of $\mathrm{Ag}$, respectively, two statistical models of the 
TABLE 3: Mean and one-way ANOVA of $R_{450 \mathrm{~nm}} \%$ and $R_{550 \mathrm{~nm}} \%$ among Groups A2-F2. Significance level $\alpha=0.05$.

\begin{tabular}{|c|c|c|c|c|c|c|c|c|}
\hline \multirow{2}{*}{ Group } & \multicolumn{3}{|c|}{ Mean $R_{450 \mathrm{~nm}} \% \pm \mathrm{SD}$} & \multirow{2}{*}{$\begin{array}{c}\operatorname{ANOVA}\left(R_{450 \mathrm{~nm}} \%\right) \\
P\end{array}$} & \multicolumn{3}{|c|}{ Mean $R_{550 \mathrm{~nm}} \% \pm \mathrm{SD}$} & \multirow{2}{*}{$\begin{array}{c}\text { ANOVA }\left(R_{550 \mathrm{~nm}} \%\right) \\
P\end{array}$} \\
\hline & $(100)$ & (110) & (111) & & $(100)$ & $(110)$ & (111) & \\
\hline A2 & $94.7 \pm 3$ & $92.4 \pm 5$ & $93.2 \pm 2$ & 0.363 & $95.8 \pm 3$ & $92.8 \pm 5$ & $96.7 \pm 3$ & 0.142 \\
\hline B2 & $87.6 \pm 5$ & $88.9 \pm 5$ & $87.0 \pm 6$ & 0.638 & $91.7 \pm 2$ & $90.3 \pm 5$ & $91.6 \pm 4$ & 0.699 \\
\hline $\mathrm{C} 2$ & $78.0 \pm 3$ & $78.4 \pm 3$ & $73.4 \pm 3$ & 0.213 & $85.1 \pm 3$ & $85.6 \pm 3$ & $83.1 \pm 3$ & 0.419 \\
\hline D2 & $66.0 \pm 4$ & $64.2 \pm 4$ & $68.8 \pm 4$ & 0.196 & $75.0 \pm 3$ & $71.2 \pm 3$ & $76.4 \pm 5$ & 0.154 \\
\hline E2 & $54.2 \pm 4$ & $58.0 \pm 3$ & $57.5 \pm 4$ & 0.225 & $62.7 \pm 3$ & $66.0 \pm 4$ & $64.1 \pm 5$ & 0.131 \\
\hline F2 & $34.6 \pm 6$ & $40.4 \pm 5$ & $39.7 \pm 5$ & 0.605 & $48.1 \pm 6$ & $53.1 \pm 5$ & $49.4 \pm 5$ & 0.625 \\
\hline
\end{tabular}

reflectance are developed to distinguish the effect of each roughness parameter.

The experimental data are treated with linear regression analysis and the two statistical equations (for $\lambda=450 \mathrm{~nm}$ and $550 \mathrm{~nm}$ ) are established for each roughness parameter.

$$
\begin{array}{ll}
R_{450 \mathrm{~nm}} \%=97.42-1.495 R_{a} & \left(R^{2}=0.944\right) \\
R_{550 \mathrm{~nm}} \%=99.82-1.307 R_{a} & \left(R^{2}=0.959\right) \\
R_{450 \mathrm{~nm}} \%=96.30-12.90 S_{d r} & \left(R^{2}=0.975\right) \\
R_{550 \mathrm{~nm}} \%=98.63-10.73 S_{d r} & \left(R^{2}=0.966\right) .
\end{array}
$$

3.6. Simulation of the Reflection from Polycrystalline Silver Films. From the comprehensive studies of morphology and crystal structure on the optical properties of single crystals, it was found that surface roughness is the most critical factor in determining the reflectance of Ag. 2D and 3D roughness parameters $\left(R_{a}\right.$ and $\left.S_{d r}\right)$ have portrayed similar linear relationship between roughness and reflectance and their resulting equations are generated in (2)-(5).

For practical applications, polycrystalline films are used. Therefore, it is important to verify the applicability and validity of the developed models based on single crystal foils using data obtained from polycrystalline films. To do so, we apply the above derived equations to two types of polycrystal Ag coatings: electroplated and physical vapour deposited Ag films.

The correlations between $R_{a}$ and reflectance and between $S_{d r}$ and reflectance of electroplated and physical vapour deposited Ag are shown in Figure 6. Expectedly, there are strong linear correlations between roughness and reflectance regardless of the types of polycrystalline Ag coatings. However, the same $R_{a}$ values have given rise to two significantly different $R_{450 \mathrm{~nm}} \%$ or $R_{550 \mathrm{~nm}} \%$, depending on the types of Ag coatings as shown in Figures 6(a) and 6(b). Physical vapour deposited $\mathrm{Ag}$ generally show lower $R_{450 \mathrm{~nm}} \%$ and $R_{550 \mathrm{~nm}} \%$ than electroplated Ag if the roughness is perceived in terms of $R_{a}$ and plotted against reflectance of the Ag.

On the other hand, if $S_{d r}$ is used as the independent variable to represent the roughness of $\mathrm{Ag}$ coatings (Figures 6(c) and 6(d)), it correlates well with both types of Ag coatings. This strongly suggests that developed surface area ratio is a better indicator to correlate with reflectance as it captures the surface texture of the coatings.
The 3D AFM images of the electrodeposited Ag and physical vapour deposited Ag samples in Figure 7 have also portrayed that both surface topographies are significantly different even though they have similar $R_{a}$ values.

In order to determine the percentage errors of the reflectance forecast in (2)-(5), the experimental $R_{450 \mathrm{~nm}} \%$ and $R_{550 \mathrm{~nm}} \%$ results of polycrystalline Ag coatings are compared with the model $R_{450 \mathrm{~nm}} \%$ or $R_{550 \mathrm{~nm}} \%$ values. The average percentage errors of the models are summarized in Table 4 .

The total average errors \% of (2) and (3) are found to be much higher than those of (4) and (5). The total average errors of using $R_{a}$ as the variable in predicting $R_{450 \mathrm{~nm}} \%$ and $R_{550 \mathrm{~nm}} \%$ are about $14.5 \%$ and $8.9 \%$, respectively. When the 3D parameter $S_{d r}$ is used for prediction, the total average error for $R_{450 \mathrm{~nm}} \%$ is $5.8 \%$ and for $R_{550 \mathrm{~nm}} \%$ is $6.0 \%$. This result has further suggested that $S_{d r}$ is a better roughness indicator in predicting the reflectance of polycrystalline silver when compared to $R_{a}$.

\section{Conclusions}

The key factors on the reflectance of silver is studied using single crystal silver foils with specific crystal orientations of $n$ (100), (110), and (111) with different surface roughness. Besides the most commonly used $2 \mathrm{D}$ parameter $R_{a}$, a hybrid parameter $S_{d r}$ which describes the 3D surface topography is also employed in the surface roughness analysis. It is found that a decrease in specular reflectance is associated with an increase in the surface roughness of single crystals, regardless of the fact that it is expressed either in $R_{a}$ or in $S_{d r}$. Moreover, after carefully separating the influence of surface roughness, it is observed that the surface roughness is the main factor in controlling the reflectance of Ag, while crystal orientation has a negligible effect on the light reflection. The mean and one-way ANOVA analysis have indicated that Ag (100), Ag (110), and Ag (111) with similar roughness are statistically the same $(P>0.05)$. When the microscopic roughness is much smaller than the wavelength, the light is reflected specularly from the surface. After treating the experimental data with linear regression analysis, two statistical equations (for $\lambda=450 \mathrm{~nm}$ and $550 \mathrm{~nm}$ ) are established for $R_{a}$ and $S_{d r}$. The accuracy of these models is verified via electrodeposited and physical vapour deposited silver films. The use of $R_{a}$ as roughness indicator to predict the reflectance of silver is highly dependent on the types of coatings whereas $S_{d r}$ is a better indicator to correlate with reflectance as it is 


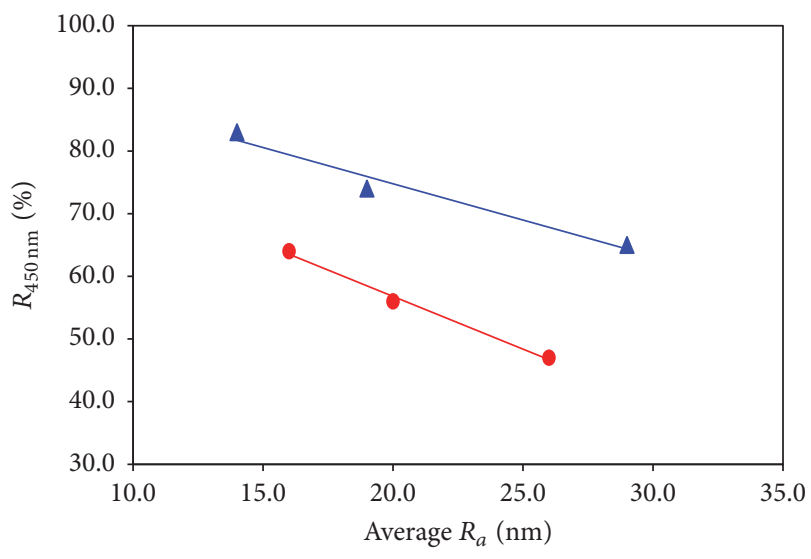

$\Delta$ Electroplating

- PVD

(a)

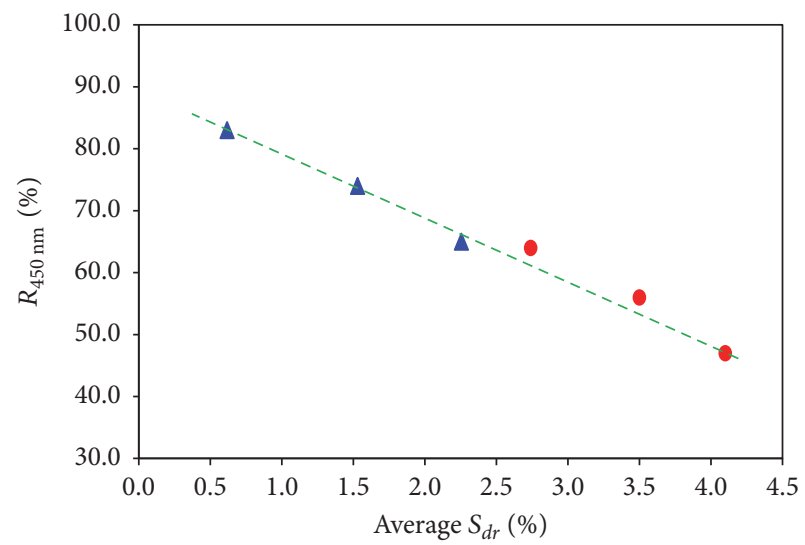

\ Electroplating

- PVD

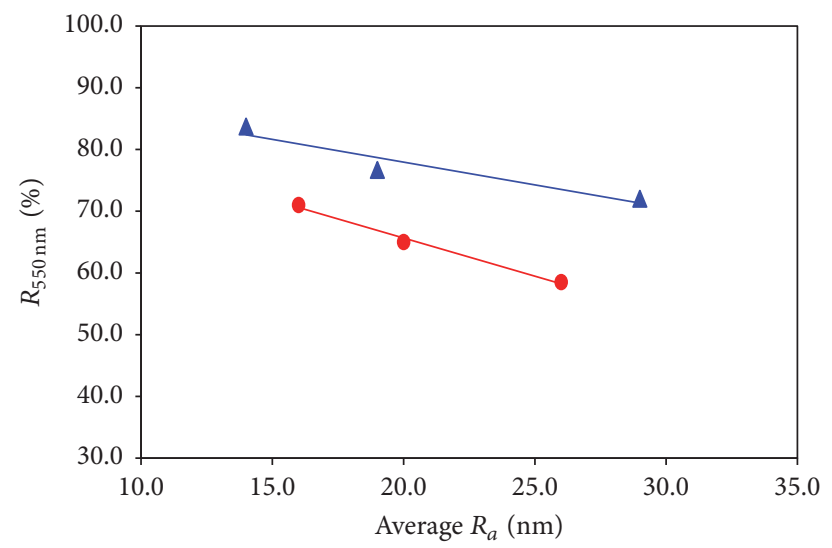

$\triangle$ Electroplating

- PVD

(b)

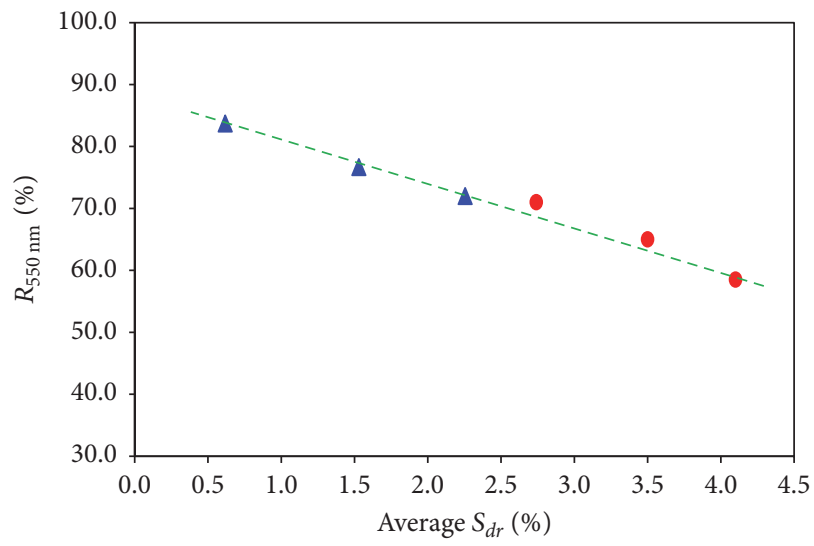

A Electroplating

- PVD

(c)

(d)

FIgURE 6: The dependence of specular reflectance of electroplated and physical vapour deposited Ag on the (a-b) average $R_{a}$; (c-d) average $S_{d r}$ at $\lambda=450 \mathrm{~nm}$ and $550 \mathrm{~nm}$, respectively.

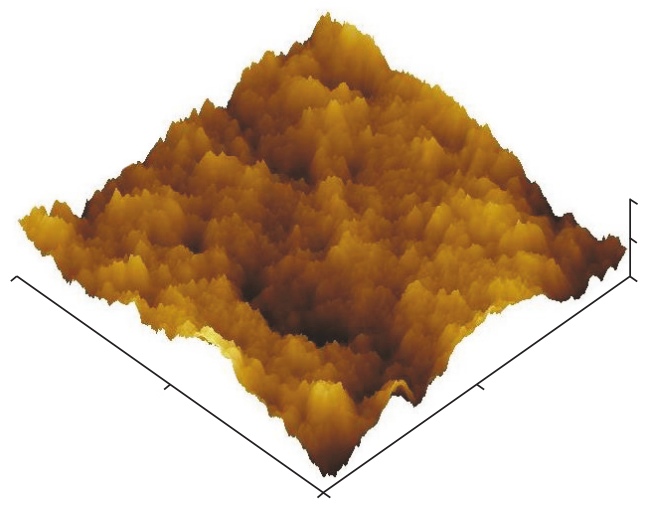

(a)

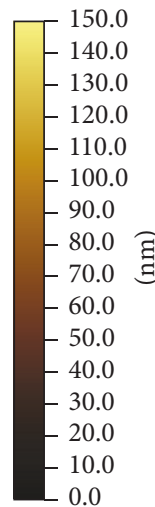

0.0

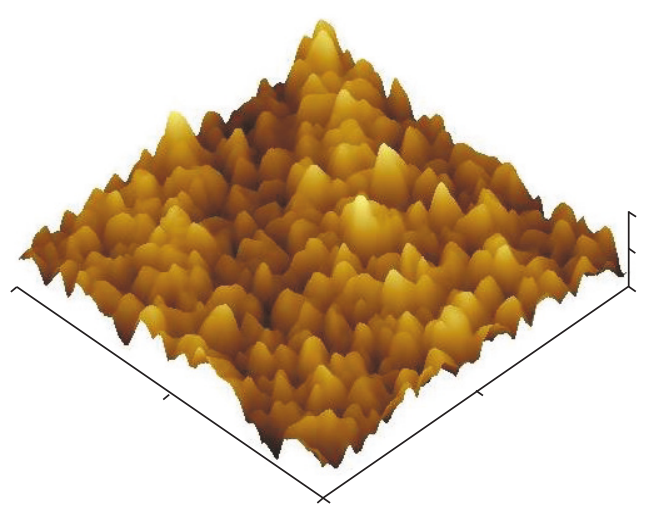

(b)

FIGURE 7: AFM images of (a) electrodeposited Ag, $R_{a}=13.8 \mathrm{~nm}, S_{d r}=2.49 \%$; (b) physical vapour deposited Ag, $R_{a}=14.5 \mathrm{~nm}, S_{d r}=4.38 \%$. 


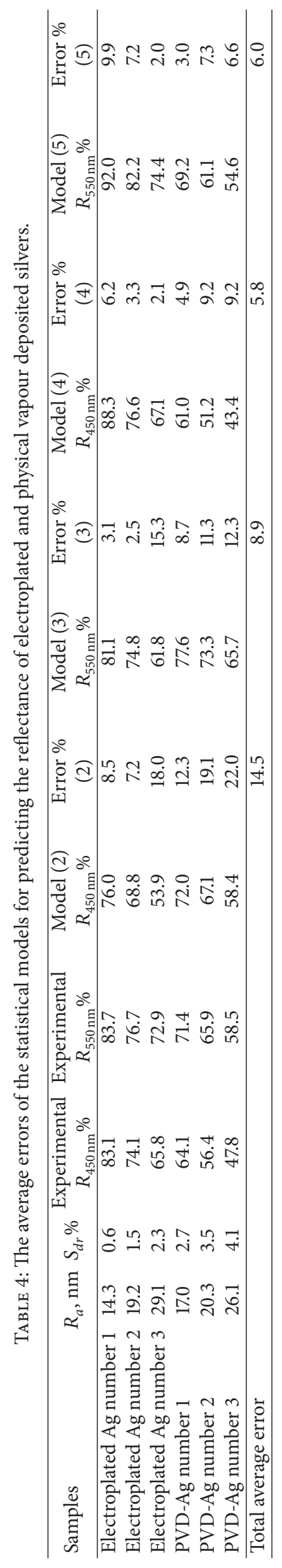


independent on the type of coatings. The reason is that $S_{d r}$ is capable of capturing the surface features in $3 \mathrm{D}$ better.

\section{Conflicts of Interest}

The authors declare that there are no conflicts of interest regarding the publication of this paper.

\section{Acknowledgments}

The authors wish to acknowledge MacDermid Enthone for their equipment and financial support. They would also like to thank Mr. Zheng Wei Xia and Ms. Lin Ji for preparing the physical vapour deposited silver.

\section{References}

[1] J.-W. Park, Y.-B. Yoon, S.-H. Shin, and S.-H. Choi, "Joint structure in high brightness light emitting diode (HB LED) packages," Materials Science and Engineering A, vol. 441, no. 1-2, pp. 357-361, 2006.

[2] K.-C. Song-Zhu, O. Tohru, Y. Hitoshi et al., "Multilayered Sn/ $\mathrm{Ag}_{3} \mathrm{Sn}$ electroplating on $\mathrm{Cu}$ alloys for high reliable electronic/ electric materials," in Proceedings of the International Conference on Electronics Packaging, ICEP, IEEE, Toyama, Japan, April 2014.

[3] S. H. Kee, W. J. Kim, and J. P. Jung, "Reflection characteristics of electroless deposited Sn-3.5Ag for LED lead frames," Surface and Coatings Technology, vol. 235, pp. 778-783, 2013.

[4] Y.-Y. Choi and T.-Y. Seong, "Morphological stability of Ag reflector for high-power GaN-based vertical light-emitting diode by addition of Ni layer," Superlattices and Microstructures, vol. 73, pp. 342-349, 2014.

[5] W.-S. Yum, J.-W. Jeon, J.-S. Sung, S. Jin, and T.-Y. Seong, "Ag/Ni/Ag multilayer reflector for GaN-based vertical lightemitting diode," Japanese Journal of Applied Physics, vol. 52, no. 5, Article ID 052101, 2013.

[6] J. H. Kim, J. H. Choi, and M. W. Shin, “Thermal and optical performance of a light-emitting-diode metal package with an integrated reflector and heat spreader structure," IEEE/OSA Journal of Display Technology, vol. 9, no. 10, pp. 794-799, 2013.

[7] S. Pimputkar, J. S. Speck, S. P. Denbaars, and S. Nakamura, "Prospects for LED lighting," Nature Photonics, vol. 3, no. 4, pp. 180-182, 2009.

[8] A. I. Zhmakin, "Enhancement of light extraction from light emitting diodes," Physics Reports, vol. 498, no. 4-5, pp. 189-241, 2011.

[9] R. Carles, C. Farcau, C. Bonafos et al., "Three dimensional design of silver nanoparticle assemblies embedded in dielectrics for raman spectroscopy enhancement and dark-field imaging," ACS Nano, vol. 5, no. 11, pp. 8774-8782, 2011.

[10] J. R. Guerreiro, N. Teixeira, V. De Freitas, M. G. Sales, and D. S. Sutherland, "A saliva molecular imprinted localized surface plasmon resonance biosensor for wine astringency estimation," Food Chemistry, vol. 233, pp. 457-466, 2017.

[11] K. Kim, W. Lee, K. Chung et al., "Molecular overlap with optical near-fields based on plasmonic nanolithography for ultrasensitive label-free detection by light-matter colocalization," Biosensors and Bioelectronics, vol. 96, pp. 89-98, 2017.
[12] K. Y. Yang, K. C. Choi, and C. W. Ahn, "Surface plasmonenhanced spontaneous emission rate in an organic lightemitting device structure: Cathode structure for plasmonic application," Applied Physics Letters, vol. 94, no. 17, Article ID 173301, 2009.

[13] P. Mottier, LEDs for Lighting Applications, Wiley, 2010.

[14] Y. Arakawa, Y. Hirayama, K. Kishino, and H. Yamaguchi, Compound Semiconductors 2001, Taylor \& Francis, 2002.

[15] B. Zheng, L. P. Wong, L. Y. Wu, and Z. Chen, "Cyclic voltammetric study of high speed silver electrodeposition and dissolution in low cyanide solutions," International Journal of Electrochemistry, vol. 2016, Article ID 4318178, 11 pages, 2016.

[16] E. D. Palik, Handbook of Optical Constants of Solids, vol. 3, Academic press, 1998.

[17] N. D. Nikolić, Z. Rakočević, and K. I. Popov, "Structural characteristics of bright copper surfaces," Journal of Electroanalytical Chemistry, vol. 514, no. 1-2, pp. 56-66, 2001.

[18] R. Weil and R. Paquin, "The relationship between brightness and structure in electroplated nickel," Journal of the Electrochemical Society, vol. 107, no. 2, pp. 87-91, 1960.

[19] N. D. Nikolić, Z. Rakočević, and K. I. Popov, "The STM analysis of a silver mirror surface," Journal of the Serbian Chemical Society, vol. 66, no. 10, pp. 723-727, 2001.

[20] N. D. Nikolić, Z. Rakočević, and K. I. Popov, "Reflection and structural analyses of mirror-bright metal coatings," Journal of Solid State Electrochemistry, vol. 8, no. 8, pp. 526-531, 2004.

[21] K. Stout, Development of Methods for the Characterisation of Roughness in Three Dimensions, Penton Press, London, Uk, 2000.

[22] K. J. Stout, W. P. Dong, E. Mainsah, N. Luo, T. Mathia, and H. Zahouani, The Development of Methods for the Characterisation of Roughness in Three Dimensions, EUR 15178, EN Commission of the European Communities, Brussels, Belgium, 1993.

[23] F. P. Bowden and D. Tabor, The Friction and Lubrication of Solids, Clarendon Press, 1950.

[24] E. Barkman, "Specular and diffuse reflectance measurements of aluminum surfaces," in Appearance of Metallic Surfaces, STP478, ASTM International, 1970.

[25] D. A. Miller, Optical Properties of Solid Thin Films by Spectroscopic Reflectometry and Spectroscopic Ellipsometry, City University of New York, 2008.

[26] O. P. Jaseentha and C. S. Menon, "Characterization of optical, electrical and structural properties of silverphthalocyanine thin films," Journal of Materials Science: Materials in Electronics, vol. 19, no. 7, pp. 602-606, 2008.

[27] M. Bass and Optical Society of America, Handbook of Optics: Devices, Measurements, and Properties, McGraw-Hill, 2 edition, 2001.

[28] V. Goossens, N. Gotzen, S. Van Gils et al., "Predicting reflections of thin coatings," Surface and Coatings Technology, vol. 204, no. 5, pp. 551-557, 2009.

[29] L. Shen, A. Ji, and J. Shen, "Silver mirror reaction as an approach to construct superhydrophobic surfaces with high reflectivity," Langmuir, vol. 24, no. 18, pp. 9962-9965, 2008. 

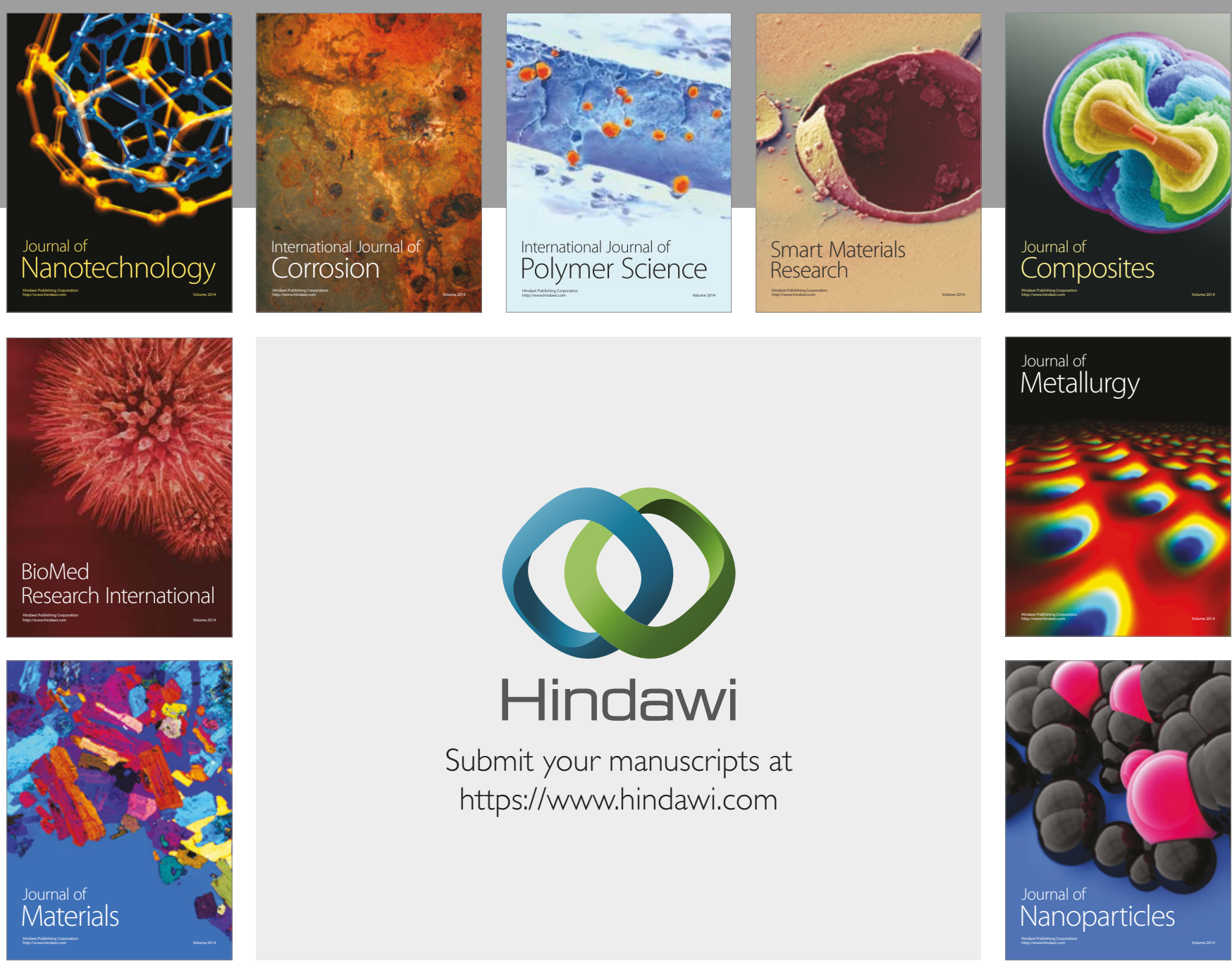

\section{Hindawi}

Submit your manuscripts at

https://www.hindawi.com
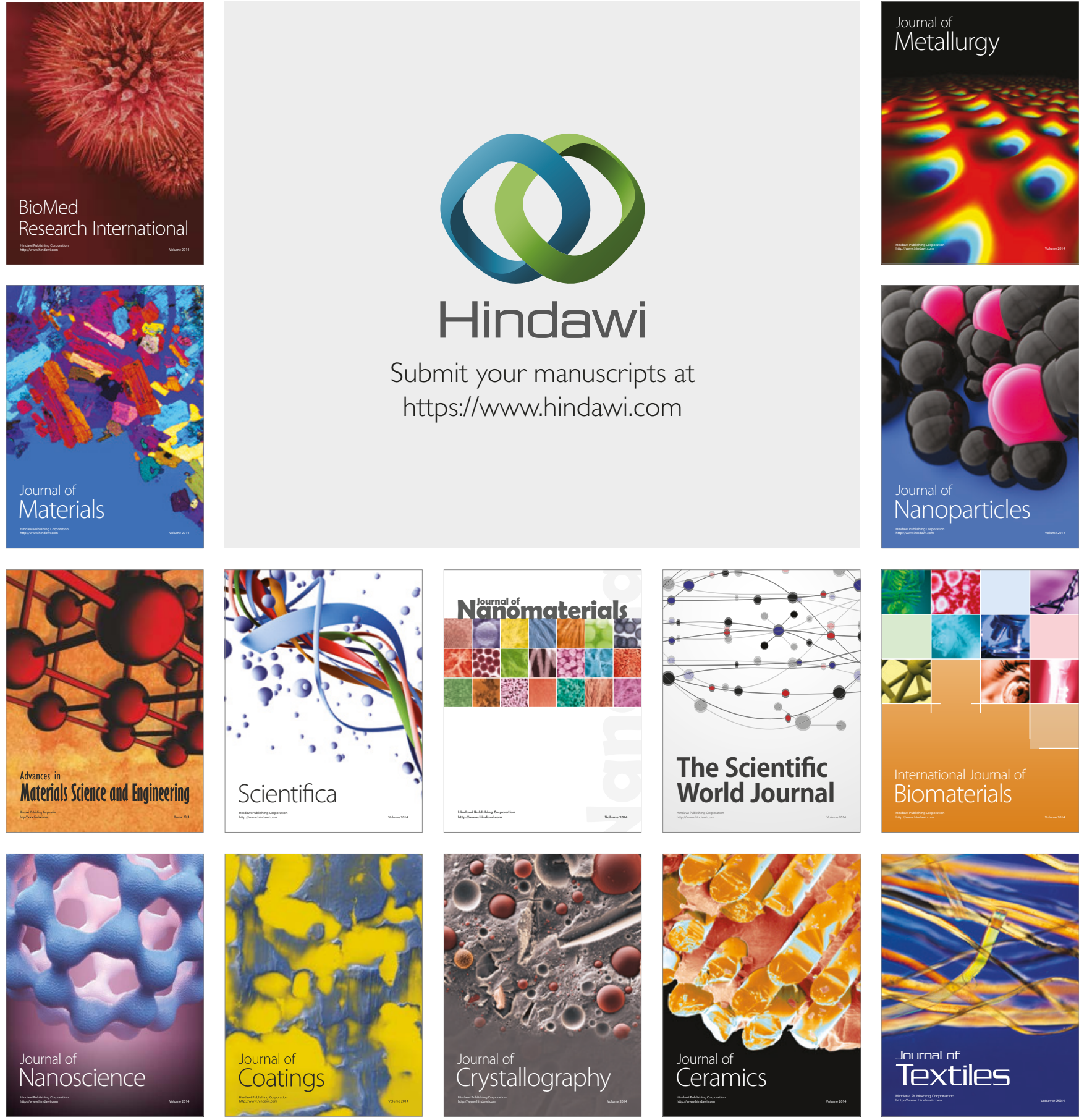

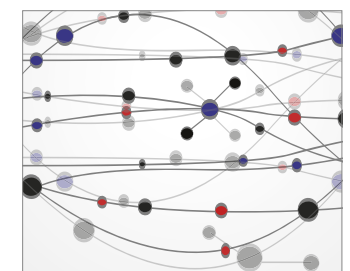

The Scientific World Journal
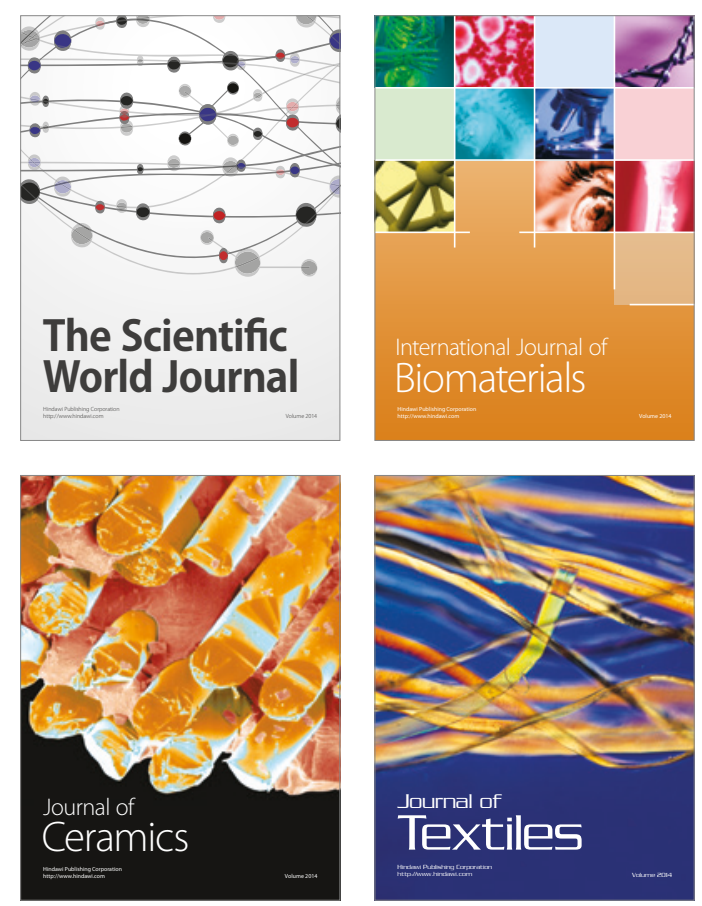